\title{
Design of maintenance structures for rural electrification with solar home systems. The case of the Moroccan program
}

\author{
L.M. Carrasco ， F.J. Martín-Campo ， L. Narvarte ，M.T. Ortuño ， B. Vitoriano
}

\begin{abstract}
A B S T R A C T
In decentralised rural electrification through solar home systems, private companies and promoting institutions are faced with the problem of deploying maintenance structures to operate and guarantee the service of the solar systems for long periods (ten years or more). The problems linked to decentralisation, such as the dispersion of dwellings, difficult access and maintenance needs, makes it an arduous task. This paper proposes an innovative design tool created ad hoc for photovoltaic rural electrification based on a real photovoltaic rural electrification program in Morocco as a special case study. The tool is developed from a mathematical model comprising a set of decision variables (location, transport, etc.) that must meet certain constraints and whose optimisation criterion is the minimum cost of the operation and maintenance activity assuming an established quality of service. The main output of the model is the overall cost of the maintenance structure. The best location for the local maintenance headquarters and warehouses in a given region is established, as are the number of maintenance technicians and vehicles required.
\end{abstract}

\section{Introduction}

Human development is a concept that has evolved over the years. In recent times, this has included access to basic services, such as electricity [1]. In the so-called developing countries, most remote rural areas do not have access to electricity grids (an example is India, that had up to 400 million people without access to electricity in 2011 [2], concentrated in the poorest states of the country [3]). Photovoltaic rural electrification (PVRE) represents, in many cases, the only hope of accessing electricity [4]. A recent study [5] shows how regions in developing countries with a low density population favour stand-alone solutions for providing access to energy. A good example is the case of remote regions in Mali [6], where PVRE has been implemented as a sustainable energy solution for rural villages. PVRE has gone through a change of scale during the last decade in terms of size and sustainability, which has given rise to the development of large-scale programs with thousands of solar home systems (SHS) and long operation and maintenance (O\&M) service periods. Bangladesh is a paradigmatic example with more than 4 million solar home systems installed up to July 2016 [7]. The fee for service financial model [8] has largely been adopted in many of these programs devolving the responsibility for the implementation and management of the programs to specialized energy service companies (ESCO), as in South Africa [9], Zambia [10] or Morocco in the PERG program [11].

Nevertheless, these ESCOs have face to the problem of decentralisation (remoteness and dispersion of the SHSs), which leads to high maintenance management costs. Traditionally the ESCOs have to design the O\&M based on assumptions such as the lifetime of the SHS components provided by the manufacturers in the datasheets or by considering the yearly maintenance cost as a ratio of between $1 \%$ and $3 \%$ of the investment cost (cost of providing and installing the SHSs), as reported in Refs. [12] and [13], without considering that these assumptions have never been properly compared with the real situation. This common practice has led to the failure of many PVRE programs in recent decades as a result of the excessive costs derived from the O\&M services, leading many ESCOs to abandon the programs because of the negative financial balances. Despite the lack of reporting, the cases of South Africa (see Refs. [9] and [14]) or Morocco, the latter well known by the author, can be cited. According to [15] among others, the main challenge for the 


\section{Acronyms}

$\begin{array}{ll}\text { Ah } & \text { Ampere hour } \\ \text { CM } & \text { Corrective Maintenance } \\ \text { ESCO } & \text { Energy Service Company } \\ \text { GAMS } & \text { General Algebraic Modelling System } \\ \text { LC } & \text { Low power Consumption light lamps } \\ \text { MTTF } & \text { Mean Time To Failure } \\ \text { O\&M } & \text { Operation and Maintenance } \\ \text { ONEE } & \text { Office National de l'Electricité et l'Eau (Morocco) } \\ \text { PERG } & \text { Program d'Electrification Rurale Globale (Morocco) } \\ \text { PM } & \text { Preventive Maintenance } \\ \text { PV } & \text { Photovoltaic } \\ \text { PVRE } & \text { Photovoltaic Rural Electrification } \\ \text { PWM } & \text { Pulse-Width Modulation (charge controller) } \\ \text { SHS } & \text { Solar Home Systems } \\ \text { Si } & \text { Silicon } \\ \text { SLI } & \text { Start-Lighting-Ignition (Battery) } \\ \text { SOC } & \text { State Of Charge } \\ \text { Wp } & \text { Watt peak }\end{array}$

fee for service model is to organise the operation and maintenance of the systems and fee collection in a financially sustainable way. In fact, decentralisation adds uncertainty the O\&M costs, depending on aspects such as the geographical density of the SHSs, their actual reliability in operating conditions, road access [16] or the different local costs (salaries, vehicles, fuel, taxes, etc.). To date no cases of the systematic use of maintenance structure design tools based on actual data are known in the field of PVRE.

To tackle this deficiency, the objective of this paper is to carry out a first approach of an ad-hoc tool for the design of maintenance structures for PVRE programs in decentralised areas, with the aim of minimising the O\&M costs. This tool has been developed for an actual PVRE program carried out in Morocco as a case study, whose inputs are not traditional assumptions but real figures as regards the actual reliability of the SHS components in this program, the O\&M structure deployed and their costs. Similar ad hoc tools have been developed in the field of rural development [17] and electrification through renewable energies [18]. However, to our knowledge, there are no reported cases in the field of O\&M in PVRE using SHSs. As this study is restricted to this particular program, it is not the aim of the authors to present this tool as a general solution but to show the potential benefits of its application to this kind of PVRE program. Adaptations of this tool could be useful for other programs with different kinds of technical features and management requirements.

The methodology used in the research work is based on the development of a mathematical optimisation model [19], applied to the PVRE program carried out in Morocco, the so-called Programme d'Electrification Rurale Global (PERG) [20], as a representative case of the fee-for-service initiatives carried out worldwide. The authors have had access to the 5-year maintenance and cost databases of the PERG program from between 2006 and 2010, provided by the ESCO, ISOFOTON, as well as the organizational and management structure deployed by the ESCO during that period. The maintenance of the PERG program has already been analysed in three previous papers in which the reliability study of the SHSs [21], the degradation of batteries and PV modules [22] and the O\&M cost assessment [23] were set out. The proposed optimisation model has been implemented using GAMS [24], one of the most powerful algebraic modelling languages, and solved using the CPLEX optimiser [25], which uses a branch-and-cut procedure [26]. The input data required has been defined together with several variables and restrictions. An objective function for computing the cost of the O\&M services is optimised, and the following outputs have been obtained:

- composition of the maintenance structure (number of technicians and vehicles),

- location and number of local agencies (local maintenance headquarters and warehouses),

- scheduling of preventive maintenance and the collection of fees,

- total cost of the services.

A prototype model has been implemented and validated in three of the nine provinces of the PERG region in order to show how this tool can be useful in helping ESCOs in the design of the maintenance structures in PVRE programs.

\section{Perg program baseline data}

The Moroccan PERG program was carried out by different ESCOs in partnership with the national utility; the Office National d'Electricite et l'Eau (ONEE) [27]. Our study focuses on the program carried out by the ESCO ISOFOTON, one of the participants in the program, which started in 2005 in a vast and mountainous area of around $200,000 \mathrm{~km}^{2}$, and with 13,452 installed SHSs.

The ONEE, as the promoter of the electrification program, established the technical, financial and organizational conditions, which the ESCO had to follow in the development of the program. The PERG was set up as a fee for service model, so the ESCOs were responsible for the marketing, sales, installation and operation \& maintenance of the SHSs in accordance with the following principles set out by the ONEE:

- The SHS cost is $90 \%$ subsidized by the utility. The remaining $10 \%$ is paid by the user through a fee collected by the ESCO (around $€ 70$ ).

- The SHS model is sized and standardized by the ONEE for the whole concession (Fig. 1).

- The user signs a subscription contract with the ONEE, and a second contract with the ESCO and the ONEE for the O\&M service.

- The time required for installing the SHS is 2 weeks from signing the contract and paying the subscription fee.

- The ONEE utility is the owner of the SHS.

- The 10-year maintenance period begins after installation. During this period the ESCO has to guarantee the service of the SHS, replacing any components that fail.

- The ESCO had to train the customers only in the use of the SHS, as the maintenance work is the responsibility of the ESCO

- During the O\&M period the user has to pay a monthly fee of around $€ 5$ (taxes not included) to the ESCO corresponding to the maintenance service

- The ESCO is required to have a free phone number available for the customers in case of a fault in the SHS or any of its components.

- The ESCO has to repair or replace every defective or malfunctioning SHS component within $48 \mathrm{~h}$ from being notified by the user (corrective maintenance).

- The ESCO must visit every SHS at least once each 6 months to check the state of the SHS and to fill the battery with distilled water (preventive maintenance).

- The ESCO has to maintain an O\&M local structure to carry out the aforementioned service. 


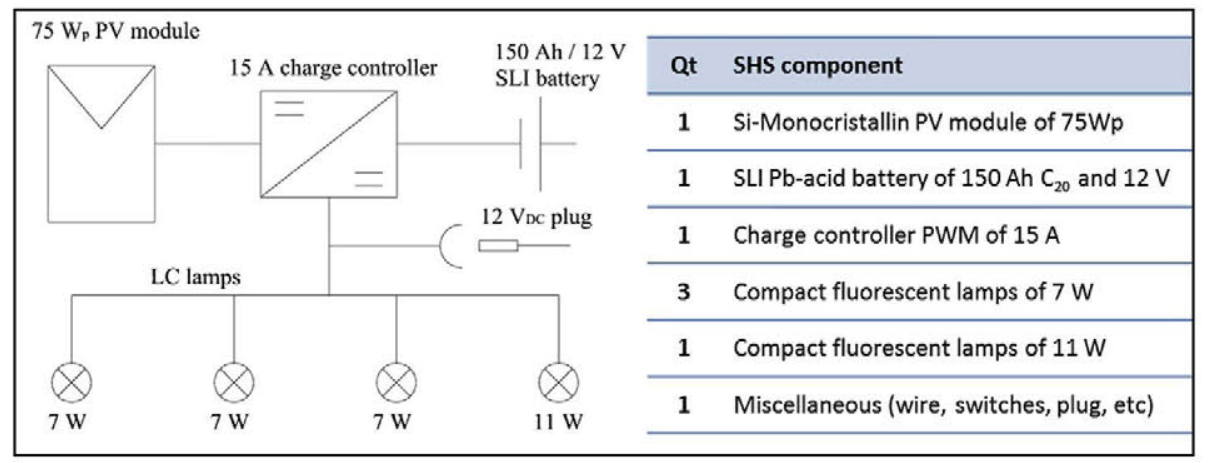

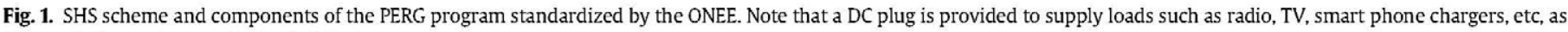
long as it does not exceed a load of $15 \mathrm{~A}$.

- In case of more than 3 months of non-payment by the user, the ESCO is able to dismount the SHS.

Note that some specifications imposed by the ONEE could have been better, the preventive maintenance for example, since two visits a year might not be enough to guarantee the replenishment of the water in the battery.

The local O\&M structure deployed by the ESCO and validated by the ONEE is detailed in Table 1. The location of the ISOFOTON PERG provinces is shown in Fig. 2. The local structure was made up of 9 local agencies, 43 employees and 19 vehicles.

The provinces are administratively divided into several rural communities $(R)$, comprising a rural centre $(r)$ and a number of dispersed villages $(V)$. The rural centre $(r)$ is the administrative capital of the community $(R)$.

The ESCO's local agency serves as both executive office and warehouse. One administrative employee is in charge of the administration tasks and remains permanently in the agency. The SHS' spare parts are stocked in the warehouse, where the O\&M technicians pick them up for the maintenance and return the failed components from the in-field SHSs. The O\&M teams are made up of two technicians and one vehicle.

The choice of the location of the local agencies adopted by the ESCO management staff was made for logistic and administrative reasons. This is why some of the agencies are located in the capital of the provinces, close to the utility bureaus, banks and regional government offices. Nevertheless, other agencies were based in rural community centres $(r)$ to be closer to the PERG users, such as in Errachidia, Al Kalaa des Sraghnas, Al Haouz or Beni Mellal (see Fig. 2).

\subsection{Operation and maintenance}

Depending on its nature, maintenance in the PERG program is differentiated into two types. Preventive maintenance (PM) consists of checking the performance of the SHS periodically. The battery must be filled with distilled water if necessary, the PV module cleaned, electric connections checked and failed lamps replaced. The PM is a deterministic process, as each SHS must be checked every 6 months, according to PERG regulations.

Corrective maintenance (CM) is carried out after prior notification from the user when he/she notices a problem in the operation of the SHS. Then, the ESCO technicians (distributed in teams of two people per vehicle) go to the dwelling within $48 \mathrm{~h}$ to repair the system or replace the failed components and return to restart the SHS.

Apart from maintenance, the technicians are also responsible for collecting the monthly fees paid by the users, which can be carried out during the maintenance visits, in the local agency, or mainly at the weekly markets organized in the rural centres ( $r$ ), known as souks. These traditional souks attract most of the surrounding rural population and are the best places to meet the SHS users, collect the monthly fees and replace failed lamps that users bring from their dwellings. Note that lamps are the only SHS component that can be replaced at the souks.

The maintenance technicians are in charge of collecting the fees at the souks every week. This task can be carried out by one technician so the other one can devote the time to maintenance services in the surrounding villages.

\section{Methodology}

The steps to build and run the modelling tool are described below. It is based on a mixed integer linear optimisation model. The input of the tool is made up of a set of parameters with which certain associated variables are calculated. An objective function is optimised according to a series of constraints that must be satisfied. Fig. 3 shows the schematic running of the optimisation model:

The model considers at least one local agency in the province located in the capital or in one of the rural centres (variable $B L_{r}$ ).

Table 1

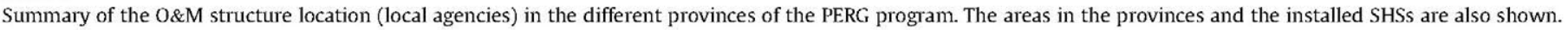

\begin{tabular}{|c|c|c|c|c|c|}
\hline Provinces & Province Capital & Area $\mathrm{km}^{2}$ & Number of SHSs & Density (SHS/ $/ \mathrm{km}^{2}$ ) & Local agency location \\
\hline Total & - & 214,531 & 13,452 & 0.063 & 9 \\
\hline Ben Slimane & Ben Slimane & 2760 & 857 & 0.311 & Ben Slimane \\
\hline Errachidia & Errachidia & 59,585 & 959 & 0.016 & Errich \\
\hline Beni Mellal & Beni Mellal & 6638 & 2723 & 0.410 & Ksiba \\
\hline Azilal & Azilal & 9800 & 1809 & 0.185 & Azilal \\
\hline Al Haouz - Marrakech & Taghnaout & 7883 & 862 & 0.109 & Ait Ourir \\
\hline Al Kalaa des Sraghnas & Al Kalaa des Sraghnas & 10,070 & 4396 & 0.437 & Ben Guerir \\
\hline Ouarzazate - Zagora & Ouarzazate & 55,298 & 841 & 0.015 & Ouarzazate \\
\hline Taroudant & Taroudant & 16,500 & 689 & 0.042 & Taroudant \\
\hline Tiznit - Guelmim - Assa-Zag & Tiznit & 45,997 & 316 & 0.007 & Tiznit \\
\hline
\end{tabular}




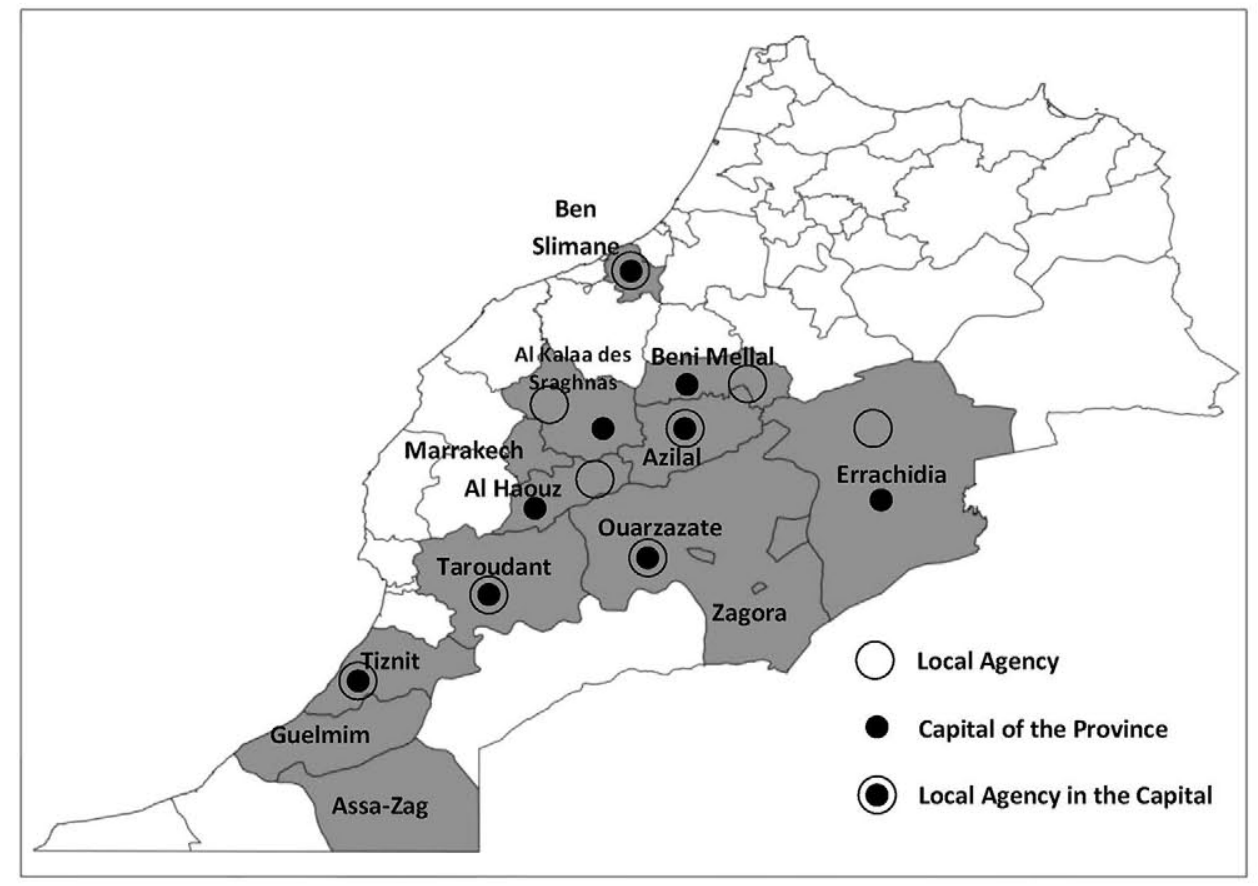

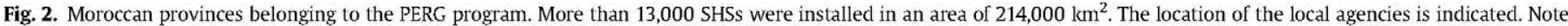
that some of them are placed in the capital of the province.

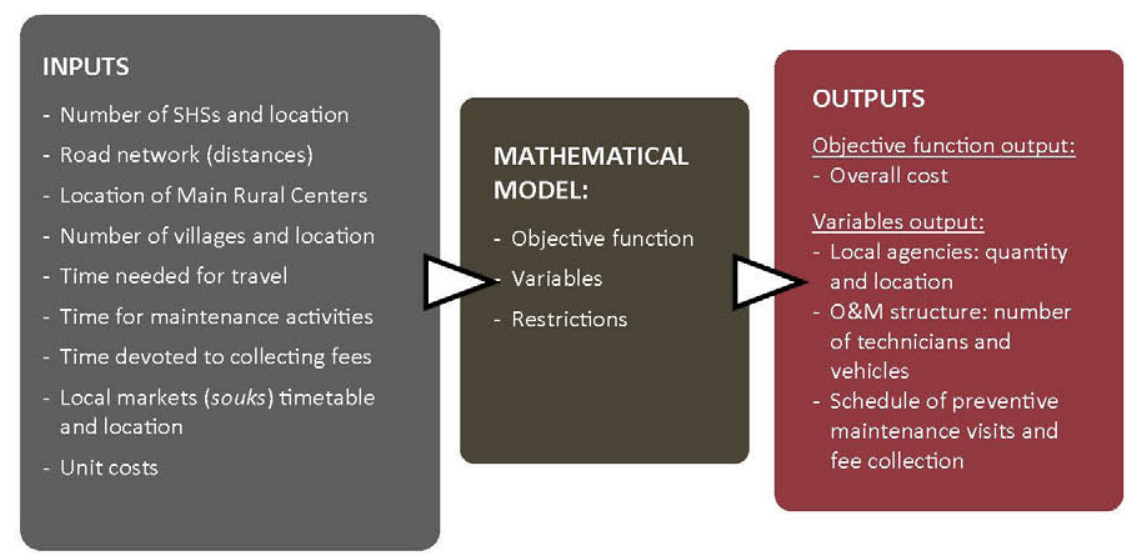

Fig. 3. Modelling tool scheme. The inputs describe the situation in the field and the outputs are the results of the modelling tool in accordance with the mathematical model.

The first decision that the model must make is the location of the local agency or agencies. Furthermore, each rural community is assigned to a local agency (variable $B A_{r, r^{\prime}}$ ) in such a way that the SHSs in the rural community are attended to by technicians from the associated local agency.

The second element to be determined is the number of vehicles associated to each local agency. They are required for the O\&M technicians to get to the villages and souks, and a vehicle is assigned for every two technicians. Each local agency has at least one vehicle (variable $N C R_{r}$ ).

The model is developed taking into account that described in section 2 and the following work dynamic:

- On the work day, the O\&M teams depart in a vehicle early in the morning from the local agency with two possible destinations: a) the rural dwellings for maintenance work; b) one of the souks for fee collection. Fig. 4 summarizes the work-day scheme. If option a), the team will go to the rural dwellings in accordance with a set plan be it PM or CM for repairs. If option b), the team will go to the souk. There, at least one of the technicians will

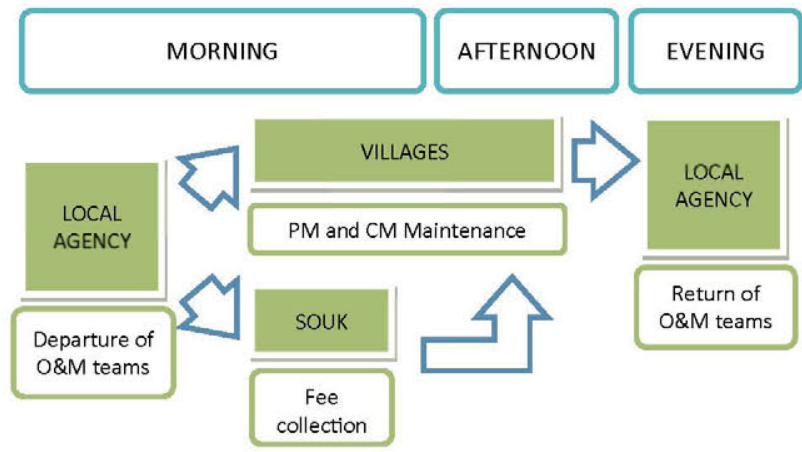

Fig. 4. O\&M teams' work-day scheme. 
remain while the other one carries out maintenance tasks in the villages of the rural community, if necessary. When the work of the day is completed, they return to the local agency.

- The technician's daily work must include the travelling time (departure from the local agency and return) as well as the maintenance service time. In no case should it exceed the established working day.

- As regards the souks, not all of them will be visited for fee collection, but just those frequented by PERG users (defined by the parameter $\left.b_{r, d}\right)$. The time devoted to the souk work is expressed by parameter $t b_{r, d}$.

- The average time required to undertake a maintenance action (tas), either preventive or corrective (from arriving at the dwelling to leaving) is also defined, taking into account the average time set out by the ESCO, ISOFOTON. Travel and time for maintenance activities take into account the daily work of the technicians, which is not allowed to exceed the established work day (dailyt).

\subsection{Input parameters and associated variables}

The optimisation model is designed to be used in a particular province. The model consists of a network of nodes representing the capital of the province and several rural communities $(R)$, which includes some small villages $(V)$. Around each village, there are few dispersed dwellings where a number of SHSs are installed.

The model will run for a given planning period or "planning horizon", $D$. To avoid problems of dimensions, this planning period will not be a complete year, but the period in which at least one visit to each rural community must be carried out. Because of the established quality of service committed to, each SHS must be visited twice a year for preventive maintenance, so each rural community will be visited at least once every six months. However, being realistic, as there is corrective maintenance to be carried out and fees to be collected, the assumption will be that each rural community has to be visited every two months. Then, the proposed planning period will be two months, corresponding to 52 working days ( 6 working days per week).

$\mathbf{R}=\{1, \ldots, R\}$ Rural communities in the province considered.

$\mathbf{V}=\{1, \ldots, V\}$ Villages in the province.
$\mathbf{D}=\{1, \ldots, D\}$ Days to be considered in the planning period.

The transport network consists of paved roads that link the main towns (almost all the rural community centres), and tracks to reach the small villages. Distances and average speed according to the type of road are used to calculate the travel time. Fig. 5 shows a schematic example of nodes in one of the PERG provinces.

The input parameters are described in Table 2:

The parameters described in Table 3 are calculated from the previous setting:

After setting the input parameters, the model variables are defined in accordance with Table 4:

\subsection{Model assumptions}

\subsubsection{Displacement scheme}

For reasons of simplicity, it has been assumed that to reach a village (V), it is always necessary to go through the rural centre, which is also supposed to be placed at the geographical centre of the rural community. Data on the exact location of the different villages $\left(n v_{r}\right)$ are not available, they are assumed to be dispersed throughout the rural community around the geographical centre at an average distance (dist'r) (see example in Fig. 6). Moreover, the model will consider that moving from a village $\left(v_{r}\right)$ to another within the same rural community $\left(\nu_{r}^{\prime}\right)$ has to be made by going through the centre.

Furthermore, it will be assumed that the displacements to rural communities from the local agencies are a round-trip, i.e., not configuring routes. The main reason for doing so is that when computing the costs of the corrective maintenance, it is very plausible that each rural community must be visited directly at least once during the planning period.

\subsubsection{Corrective maintenance}

As corrective maintenance is a stochastic event, it cannot be planned in advance. The model sizes the maintenance structure (number of technician teams) to carry out preventive maintenance (PM) and fee collection. Once this is done, the remaining time in the working days is counted and compared with the time required for carrying out the corrective maintenance (CM). If the remaining time is not enough to guarantee the $\mathrm{CM}$, it will be necessary to increase the number of technician teams. As regards corrective

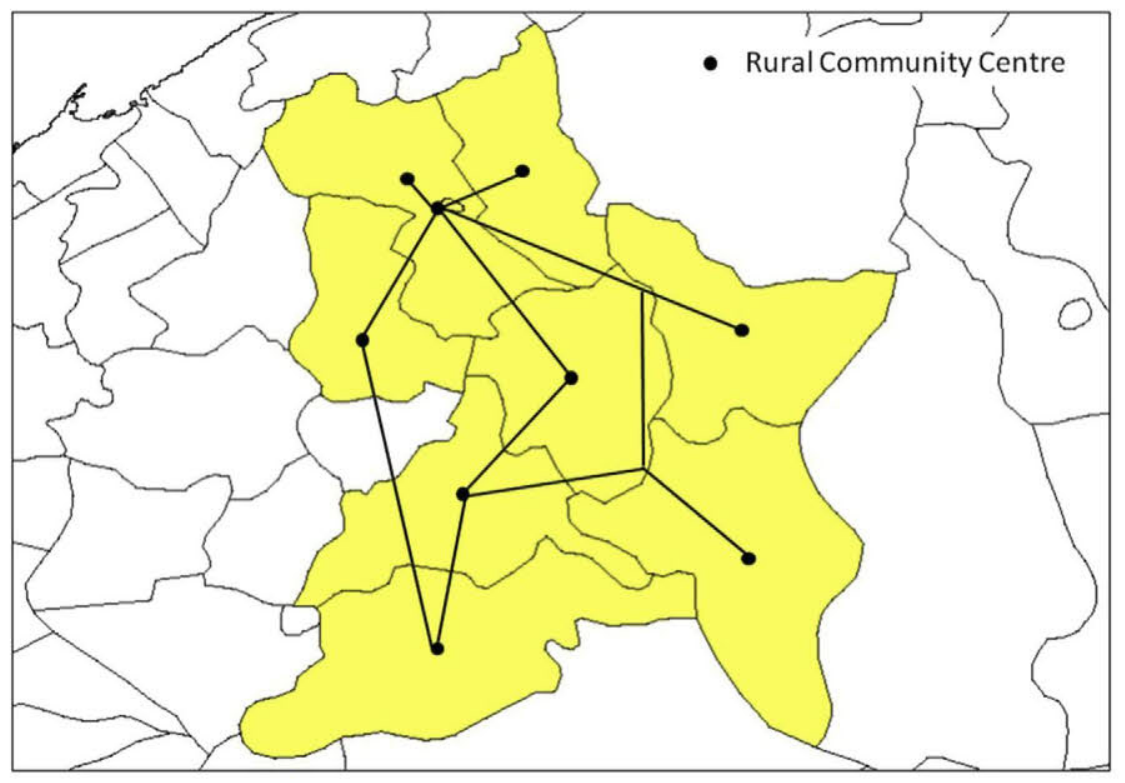

Fig. 5. Example of a network. Each black point represents a rural centre. Segments outline the paved roads linking the rural centres. 
Table 2

Input parameters.

\begin{tabular}{|c|c|}
\hline$n v_{r}$ & Number of villages in the rural community $r \in \mathbf{R}$. \\
\hline$a_{y, r}$ & $\begin{array}{l}\text { Element of a } 0-1 \text { matrix which is equal to } 1 \text { if village } v \in \mathbf{V} \\
\text { belongs to the rural community } r \in \mathbf{R} \text { and } 0 \text { otherwise. }\end{array}$ \\
\hline$n s h s_{v}$ & Number of SHSs in the village $v \in \mathbf{V}$. \\
\hline dist $_{r, r^{\prime}}$ & Distance between the rural centres $r, r^{\prime} \in \mathbf{R}$. \\
\hline$t d_{r, r^{\prime}}$ & Time needed for travelling between the rural centres $r, r^{\prime} \in \mathbf{R}$. \\
\hline $\operatorname{dist}_{r}^{\prime}$ & $\begin{array}{l}\text { Average of distances from the rural centre of the rural } \\
\text { community } r \in \mathbf{R} \text { to each of its villages } v \in \mathbf{V} \text {. }\end{array}$ \\
\hline$t d_{r}^{\prime}$ & $\begin{array}{l}\text { Average time for the displacements within the same rural } \\
\text { community } r \in \mathbf{R} \text {. }\end{array}$ \\
\hline tas & Time needed to attend to a solar home system. \\
\hline$b_{r, d}$ & $\begin{array}{l}\text { Element of a } 0-1 \text { matrix which is equal to } 1 \text { if there is a market } \\
\text { (souk) in the rural community } r \in \mathbf{R} \text { on day } d \in \mathbf{D} \text { and } \\
0 \text { otherwise. }\end{array}$ \\
\hline$t b_{r, d}$ & $\begin{array}{l}\text { Time devoted to the market (souk) located in the rural } \\
\text { community } r \in \mathbf{R} \text { on day } d \in \mathbf{D} \text {. }\end{array}$ \\
\hline numc & $\begin{array}{l}\text { Maximum number of vehicles available to be distributed } \\
\text { between the local agencies. }\end{array}$ \\
\hline dailyt & Length of the technician's working day. \\
\hline$c m c_{r}$ & $\begin{array}{l}\text { Cost for locating a local agency in the Capital of the rural } \\
\text { community } r \in \mathbf{R} \text {. }\end{array}$ \\
\hline$c n c_{r}$ & $\begin{array}{l}\text { Cost for assigning a team (vehicle and two technicians) to the } \\
\text { possible local agency located in the rural community } r \in \mathbf{R} \text {. }\end{array}$ \\
\hline ctr & Travelling cost per unit of distance. \\
\hline
\end{tabular}

Table 3

Parameters calculated according to the inputs introduced.

\begin{tabular}{|c|c|}
\hline$n s y s_{v}$ & $\begin{array}{l}\text { Number of SHSs to be attended during the planning horizon } \\
\text { (proportional part of the total SHSs to be visited), computed as }\end{array}$ \\
\hline & $n s y s_{v}=\left[2 \cdot n s h s_{y} \frac{D}{365}\right]$ \\
\hline$d i s t_{r}^{\prime \prime}$ & $\begin{array}{l}\text { Average of distance assigned to an SHS in the rural community } \\
r \in \mathbf{R} \text {, computed as dist" } t_{r}^{\prime \prime}=\frac{d i s t_{r}^{\prime} n v_{r}}{\sum_{v \in V \mid \pi_{v r}-1} n s y S_{v}}\end{array}$ \\
\hline$t d_{r}^{\prime}$ & 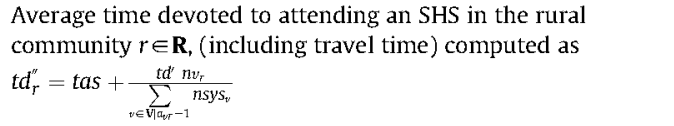 \\
\hline
\end{tabular}

maintenance, the authors have published a previous paper [21] in which the reliability of the SHS components belonging to the PERG program has been achieved and the failure rate of every component is known in terms of percentage of devices that fail per unit time. The optimisation model will incorporate the corrective actions as part of the preventive maintenance just by adding the expected number of corrective actions to be carried out during the planning period corresponding to the schedule. For example, if a corrective

Table 4

Model variables. They represent the decisions to be taken.

\begin{tabular}{|c|c|}
\hline$B L_{r}$ & $\begin{array}{l}0 \text { - } 1 \text { variable which equals } 1 \text { if a local agency is located on the } \\
\text { rural community } r \in \mathbf{R} \text { and } 0 \text {, otherwise. }\end{array}$ \\
\hline$B A_{\tau, r}$ & $\begin{array}{l}0-1 \text { variable which equals } 1 \text { if a possible local agency located on } \\
r \in \mathbf{R} \text { goes to the rural community } r^{\prime} \in \mathbf{R} \text { and } 0 \text {, otherwise. }\end{array}$ \\
\hline$N C R_{r}$ & $\begin{array}{l}\text { Number of vehicles assigned to the possible local agency located } \\
\text { in the rural community } r \in \mathbf{R} \text {. }\end{array}$ \\
\hline$B R_{r, r^{\prime}, d}$ & $\begin{array}{l}0 \text { - } 1 \text { variable which equals } 1 \text { if the rural community } r^{\prime} \in \mathbf{R} \text { is } \\
\text { visited from the possible local agency located in the rural } \\
\text { community } r \in \mathbf{R} \text { on day } d \in \mathbf{D} \text { and } 0 \text {, otherwise. }\end{array}$ \\
\hline$N S R_{r^{\prime}, d}$ & $\begin{array}{l}\text { Number of solar home systems in the rural community } r^{\prime} \in \mathbf{R} \\
\text { attended to on day } d \in \mathbf{D} \text {. }\end{array}$ \\
\hline$N C T_{r, r^{\prime}, d}$ & $\begin{array}{l}\text { Number of vehicles travelling to the rural community } r^{\prime} \in \mathbf{R} \\
\text { from a possible local agency located in the rural community } \\
r \in \mathbf{R} \text { on day } d \in \mathbf{D} \text {. }\end{array}$ \\
\hline$T M_{r, r^{\prime}, d}$ & $\begin{array}{l}\text { Time spent in the rural community } r^{\prime} \in \mathbf{R} \text { coming from the } \\
\text { possible local agency located in the rural community } r \in \mathbf{R} \text { on } \\
\text { day } d \in \mathbf{D} \text {. }\end{array}$ \\
\hline
\end{tabular}

maintenance service is required in a certain village, as set out in the established quality service specifications, it must be carried out within $48 \mathrm{~h}$, and all the preventive maintenance services scheduled in this village for the next few days will be carried out the day of the corrective maintenance, and other tasks should be rescheduled.

\subsection{Criteria and objective function}

The model is developed under the criterion, firstly, of giving a certain quality of maintenance service. Previous hypotheses are assumed in order to ensure that, with the resources available and the cost, it will be possible to carry out the maintenance operations with the degree of quality stipulated in the contract. Thus, these hypotheses and the service conditions will be included in the model as hard constraints (constraints that must be taken into account by any feasible solution). Then, the cost has to be minimised, assuming a fixed level of service. The total cost is made up of the cost of locating local agencies, the cost of teams (vehicles + technicians) and the cost of travelling:

- Costs related to the location of local agencies, such as renting offices, personnel resources and other operational costs (it includes a fixed cost per province and a variable cost per number of local agencies established):

$\sum_{r \in \mathbf{R}} c m c_{r} B L_{r}$

- Costs related to the number of teams assigned to each local agency (it includes the annual fixed costs of the vehicle, such as insurance and maintenance, and the salaries and some expenses of the two technicians):

$\sum_{r \in \mathbf{R}} C n C_{r} N C R_{r}$

- Costs related to travelling (fuel), made up of journeys covered from the local agencies to rural communities and from rural communities to villages:

$2 c t r \sum_{r, r^{\prime} \in \mathbf{R}} \sum_{d \in \mathbf{D}}$ dist $_{r, r^{\prime}} N C T_{r, r^{\prime}, d}+2 c t r \sum_{r^{\prime} \in \mathbf{R}} \sum_{d \in \mathbf{D}} \operatorname{dist}_{r^{\prime}}^{\prime \prime} N S R_{r^{\prime}, d}$

Then, the objective function to be optimised is the aggregated sum of the previous costs:

$$
\begin{aligned}
& \min \left[\sum_{r \in \mathbf{R}} c m c_{r} B L_{r}+\sum_{r \in \mathbf{R}} c n c_{r} N C R_{r}+2 c t r \sum_{r, r^{\prime} \in \mathbf{R}}\right. \\
& \left.\times \sum_{d \in \mathbf{D}} \operatorname{dist}_{r, r^{\prime}} N C T_{r, r^{\prime}, d}+2 c t r \sum_{r^{\prime} \in \mathbf{R}} \sum_{d \in \mathbf{D}} d i s t_{r^{\prime}}^{\prime \prime} N S R_{r^{\prime}, d}\right]
\end{aligned}
$$

\subsection{Definition of constraints}

The constraints defined must guarantee that the service is provided with a given level of quality and the schedule is robust enough to be adapted in real operations. Besides the assumptions included at the beginning of this section, two preventive maintenance visits are also made to each SHS per year. A proportional number of SHSs will be considered in the planning period model (in our case, two months $\mathrm{D}=52$ days).

So, the main constraints included in the model are as follows: 


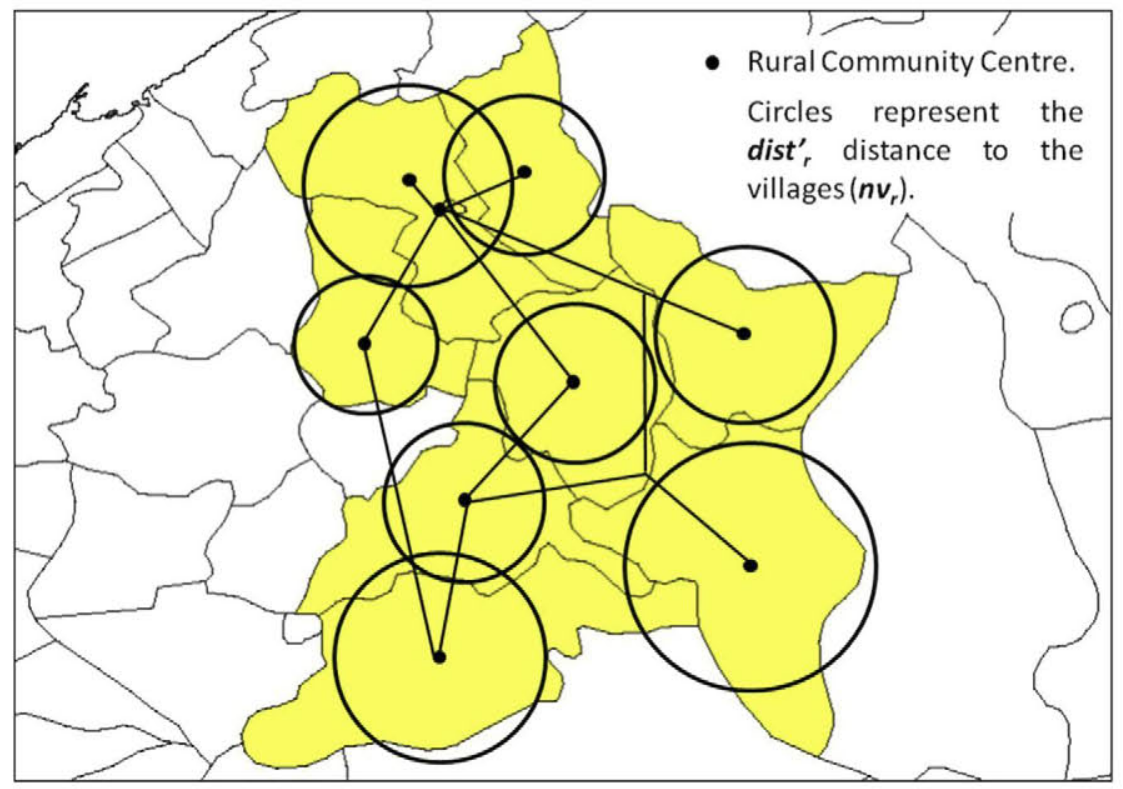

Fig. 6. Assumed distribution of rural communities and villages.

1) At least one local agency must be located in the province:

$$
\sum_{r \in \mathbf{R}} B L_{r} \geq 1
$$

2) Each rural community $r^{\prime} \in \mathbf{R}$ must be visited from one and only one local agency.

$$
\sum_{r \in \mathbf{R}} B A_{r, r^{\prime}}=1, \forall r^{\prime} \in \mathbf{R}
$$

3) A rural community $r^{\prime} \in \mathbf{R}$ is assigned to a possible local agency only if this is established, and, if so, it can be visited on day $d \in \mathbf{D}$.

$B R_{r, r^{\prime}, d} \leq B A_{r, r^{\prime}} \leq B L_{r}, \forall r, r^{\prime} \in \mathbf{R}, d \in \mathrm{D}$

4) If there is a souk on day $d \in \mathbf{D}$ in the rural community $r^{\prime} \in \mathbf{R}$, then it must be visited.

$\sum_{r \in \mathbf{R}} B R_{r, r^{\prime}, d} \geq b_{r^{\prime}, d}, \forall r^{\prime} \in \mathbf{R}, \forall d \in \mathbf{D}$

5) All the SHSs included in a rural community $r^{\prime} \in \mathbf{R}$ and contemplated in the planning horizon must be visited:

$\sum_{d \in \mathbf{D}} N S R_{r, d}=\sum_{v \in \mathbf{V}} a_{v, r^{\prime}}$ nsys $_{v}, \forall r^{\prime} \in \mathbf{R}$

6) On day $d \in \mathbf{D}$, the SHSs of a rural community $r^{\prime} \in \mathbf{R}$ can be visited only if that rural community is visited on that day

$N S R_{r^{\prime}, d} \leq \sum_{v \in \mathbf{V}} a_{v, r^{\prime}} n s y s_{v} \sum_{r^{\prime} \in R} B R_{r, r^{\prime}, d}, \forall r \in \mathbf{R}, d \in \mathrm{D}$

7) Vehicles can be assigned to a rural community if there is a local agency located in that rural community.
$N C R_{r} \leq$ numcBL $_{r}, \forall r \in \mathbf{R}$

8) The number of vehicles used for displacements from one local agency to a rural community $r^{\prime} \in \mathbf{R}$ on day $d \in \mathbf{D}$ is limited by the number of vehicles assigned to the local agency.

$N C T_{r, r^{\prime}, d} \leq N C R_{r}, \forall r, r^{\prime} \in \mathbf{R}, \forall d \in \mathbf{D}$

9) The time spent in the rural community $r^{\prime} \varepsilon R$ on day $d \varepsilon D$ is the maximum of the time spent in the souk and the time spent carrying out SHS maintenance. For rural communities where a local agency is located, it is not necessary to take the souk time into account since users are attended to directly by the local agency staff.

$T M_{r, r^{\prime}, d} \geq t b_{r, d}\left(1-B L_{r}\right)-M\left(1-B R_{r, r^{\prime}, d}\right), \forall r, r^{\prime} \in \mathbf{R}, \forall d \in \mathbf{D}$

$T M_{r, r^{\prime}, d} \geq t d_{r}^{\prime \prime} N S R_{r^{\prime}, d}-M\left(1-B R_{r, r^{\prime}, d}\right), \forall r, r^{\prime} \in \mathbf{R}, \forall d \in \mathbf{D}$

10) The time spent in the rural community $r^{\prime} \in \mathbf{R}$ by all the vehicles sent there, plus the travelling time to the rural community of all the vehicles (round-trip) must be less than the working day of the technicians.

$T M_{r, r^{\prime}, d}+2 t d_{r, r^{\prime}} N C T_{r, r^{\prime}, d} \leq$ dailyt $N C T_{r, r^{\prime}, d}, \forall r, r^{\prime} \in \mathbf{R}, \forall d \in \mathbf{D}$

11) The total time spent on day $d \in \mathbf{D}$ by the teams assigned to a local agency is at most the length of their workdays'.

$\sum_{r^{\prime} \in \mathbf{R}}\left(t d_{r, r^{\prime}} N C T_{r, r^{\prime}, d}+T M_{r, r^{\prime}, d}\right) \leq$ dailytNCR $, \forall r \in \mathbf{R}, \forall d \in \mathbf{D}$

These constraints, together with the objective function of Section 3.3, make up a mixed integer linear optimisation model. Due to the integrality of some of the variables, the model is hard to solve in a reasonable computational time, so the constraints help to 
Table 5

Parameters for the rural communities in Azilal.

\begin{tabular}{|c|c|c|c|c|c|c|}
\hline \multicolumn{2}{|c|}{ (R) Rural communities } & \multirow{2}{*}{$\frac{n \text { nsys }_{v}}{22}$} & \multirow{2}{*}{$\frac{\operatorname{dist}_{r}^{\prime}(\mathrm{km})}{0}$} & \multirow{2}{*}{$\frac{t d_{r}^{\prime}(\min )}{0}$} & \multirow{2}{*}{$\frac{n v_{r}}{0}$} & \multirow{2}{*}{$\frac{b_{r, d} \text { (Souk) }}{1 \text { (Thursday) }}$} \\
\hline 0 & Azilal (Capital) & & & & & \\
\hline 1 & Afourer & 124 & 4.1 & 8 & 2 & 0 \\
\hline 2 & Agoudi N'lkhair & 361 & 7.5 & 15 & 9 & 0 \\
\hline 3 & Ait Abbas & 22 & 8.3 & 17 & 6 & 1 (Friday) \\
\hline 4 & Ait Bououli & 80 & 11.1 & 22 & 5 & 0 \\
\hline 5 & Ait Mazigh & 1 & 6.9 & 14 & 3 & 1 (Monday) \\
\hline 6 & Ait M'hamed & 8 & 13.0 & 26 & 1 & 0 \\
\hline 7 & Ait Taguella & 43 & 6.0 & 12 & 5 & 0 \\
\hline 8 & Ait Tamlil & 3 & 12.8 & 26 & 12 & 0 \\
\hline 9 & Anergui & 10 & 10.5 & 21 & 2 & 0 \\
\hline 10 & Beni Hassan & 23 & 6.1 & 12 & 1 & 0 \\
\hline 11 & Bin El Ouidane & 80 & 6.8 & 14 & 1 & 0 \\
\hline 12 & Bni A'yat & 19 & 6.4 & 13 & 8 & 0 \\
\hline 13 & Bzou & 3 & 8.2 & 16 & 1 & 0 \\
\hline 14 & Foum Jamaa & 8 & 5.3 & 11 & 2 & 0 \\
\hline 15 & Imlil & 55 & 5.4 & 11 & 2 & 0 \\
\hline 16 & Isseksi & 10 & 7.8 & 16 & 3 & 1 (Friday) \\
\hline 17 & Moulay Aissa Ben Driss & 71 & 6.9 & 14 & 2 & 0 \\
\hline 18 & Ouaouizeght & 18 & 5.3 & 11 & 3 & 1 (Wednesday) \\
\hline 19 & Ouaoula & 1 & 8.1 & 16 & 6 & 1 (Wednesday) \\
\hline 20 & Rfala & 5 & 7.5 & 15 & 1 & 0 \\
\hline 21 & Tabante & 66 & 10.3 & 21 & 1 & 0 \\
\hline 22 & Tabaroucht & 90 & 5.9 & 12 & 2 & 0 \\
\hline 23 & Tamda Noumarcid & 2 & 7.3 & 15 & 6 & 1 (Thursday) \\
\hline 24 & Tanante & 16 & 6.9 & 14 & 1 & 1 (Tuesday) \\
\hline 25 & Taounza & 8 & 5.9 & 12 & 3 & 0 \\
\hline 26 & Tidili Fatouaka & 349 & 5.0 & 10 & 2 & 0 \\
\hline 27 & Tilougguite & 9 & 12.0 & 24 & 12 & 1 (Saturday) \\
\hline 28 & Timoulilte & 302 & 4.1 & 8 & 3 & 0 \\
\hline 29 & Zaouiat ahansal & 22 & 16.7 & 33 & 11 & 1 (Monday) \\
\hline
\end{tabular}

Table 6

Time parameters for Azilal. These parameters are average values and have been provided by the ESCO ISOFOTON.

\begin{tabular}{ll} 
Time needed to attend to a solar home system (tas) & $20 \mathrm{~min}$ \\
Time devoted to the market located in the rural community $\left(t b_{r, d}\right)$ & $4 \mathrm{~h}$ \\
Maximum time allowed in a working day (dailyt) & $9 \mathrm{~h}$ \\
\hline
\end{tabular}

Table 7

Costs based on real expenses in 2010 in Azilal, considering associated costs, including other secondary expenses linked to the main concept (i.e. telephone and fax costs of the local agency).

\begin{tabular}{ll}
\hline Concept (comprising associated costs) & Annual unit cost $(€)$ \\
\hline Local agency & 3521 \\
Agency head & 6589 \\
Administrative employee & 3068 \\
O\&M technician & 4295 \\
Vehicle (type: van) & 3462 \\
Vehicle (type: $4 \times 4)$ & 6402 \\
Vehicle fuel consumption $(€ / 100 \mathrm{~km})$ & 5.31 \\
\hline
\end{tabular}

Table 8

Optimisation model results compared to the actual data for Azilal.

\begin{tabular}{lll}
\hline Output parameters & Model results & ESCO real data \\
\hline Local Agency location & $\mathrm{R}=0(1$ local agency located in 1 local agency located in \\
$\quad\left(B L_{r}\right)$ & AZILAL) & AZILAL \\
Vehicles $\left(N C R_{r}\right)$ & 2 vehicles & 2 vehicles \\
O\&M technicians & 4 technicians & 4 technicians \\
$\begin{array}{c}\text { Local structure costs } \\
\quad(€ / \text { year) }\end{array}$ & 48,011 & 48,011 \\
$\begin{array}{c}\text { Travel costs (fuel) } \\
\quad(€ / \text { year) }\end{array}$ & 7257 & 8687 \\
O\&M annual cost $(€)$ & 55,268 & 56,698 \\
\hline
\end{tabular}

accelerate the process (although their sense is redundant) have been included. The model has been implemented in the GAMS algebraic modelling system, linked to the CPLEX optimiser, which uses a branch-and-cut procedure.

\section{Model application}

The model has been applied in three of the nine provinces of the PERG program: Azilal, Al Kalaa des Sraghnas and Ben Slimane. The results are compared to the real maintenance structure deployed by the ESCO and the real associated costs.

\subsection{Example 1: Azilal}

Tables 5-7 summarize the input parameters in the case of Azilal. Note that travelling time $\left(t d_{r}^{\prime}\right)$ corresponds to average values measured by the ESCO, ISOFOTON.

Other inputs are the distances (dist $t_{r, r^{\prime}}$ expressed in $\mathrm{km}$ ) and travel times $\left(t d_{r, r}\right.$ expressed in minutes) between the different rural communities $(R)$.

Table 8 summarizes the results of the optimisation of the model:

The results show that both the model solution and ESCO real data are similar (O\&M annual costs differ by $2.5 \%$, which is not significant).

As regards the corrective maintenance, the model concludes that after assigning all the preventive maintenance, there will be around 283 h per year available for corrective maintenance services. According to the previous reliability study [21], during the 10 years of maintenance, the highest number of corrective maintenance services will take place during the sixth year, in which the failure rate of the batteries reaches the maximum (see Table 9). If lamps are replaced in the souks, the number of corrective maintenance visits during the sixth year corresponds to 397 batteries +62 charge controllers $=459 \mathrm{CM}$ actions. If the time dedicated to 
Table 9

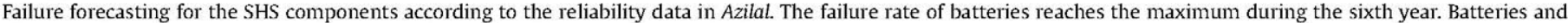
charge controllers are replaced in the user dwelling while lamps are replaced in the souk.

\begin{tabular}{|c|c|c|c|c|c|c|c|c|c|c|}
\hline Year & 1 & 2 & 3 & 4 & 5 & 6 & 7 & 8 & 9 & 10 \\
\hline Batteries & 8 & 62 & 186 & 286 & 369 & 397 & 361 & 305 & 272 & 278 \\
\hline Charge controllers & 12 & 39 & 62 & 62 & 62 & 62 & 62 & 62 & 51 & 24 \\
\hline Total & 20 & 101 & 248 & 348 & 431 & 459 & 423 & 367 & 323 & 302 \\
\hline
\end{tabular}

Table 10

Optimisation model results compared to the actual data for Al Kalaa des Sraghnas.

\begin{tabular}{lll}
\hline Output parameters & Model results & ESCO real data \\
\hline Local Agency & $\mathrm{R}=18$ (1 local agency & 1 local agency located in \\
$\quad$ location $\left(B L_{r}\right)$ & located in JAAFRA) & BEN GUERIR \\
Vehicles $\left(N C R_{r}\right)$ & 3 vehicles & 4 vehicles \\
O\&M technicians & 6 technicians & 8 technicians \\
Local structure costs & 59,170 & 66,875 \\
$\quad(€ /$ year) & & 23,280 \\
Travel costs (fuel) & 13,413 & \\
$\quad(C /$ year) & & 90,155 \\
$\begin{array}{c}\text { O\&M annual cost } \\
\text { (C) }\end{array}$ & 72,583 & \\
\hline
\end{tabular}

maintenance is $20^{\prime}$, around $153 \mathrm{~h}$ will be necessary, less than the $283 \mathrm{~h}$ available, according to the model results. For the other years during the maintenance period, the time available for $\mathrm{CM}$ will be even longer.

\subsection{Example 2: Al Kalaa des Sraghnas}

In the case of the province of Al Kalaa des Sraghnas, with 55 rural communities and 4396 SHSs, the results of the model optimisation are shown in Table 10, taking into account the same time parameters as defined in Table 6:

First of all, the model has been applied by establishing the real configuration in the province (1 local agency located in Ben Guerir, 4 vehicles and 8 technicians), meaning a cost of $€ 82,413$ which represents $9 \%$ less than the overall cost of the ESCO. However, the model is able to find a better configuration if there is one, as is the case in this province.

The results of the model optimisation (without establishing any variables) indicate a lower annual maintenance cost of $19.5 \%$ with respect to the real ESCO data, due to the reduction of 1 maintenance team and the optimisation of the maintenance displacements, in addition to the relocation of the local agency (Fig. 7).

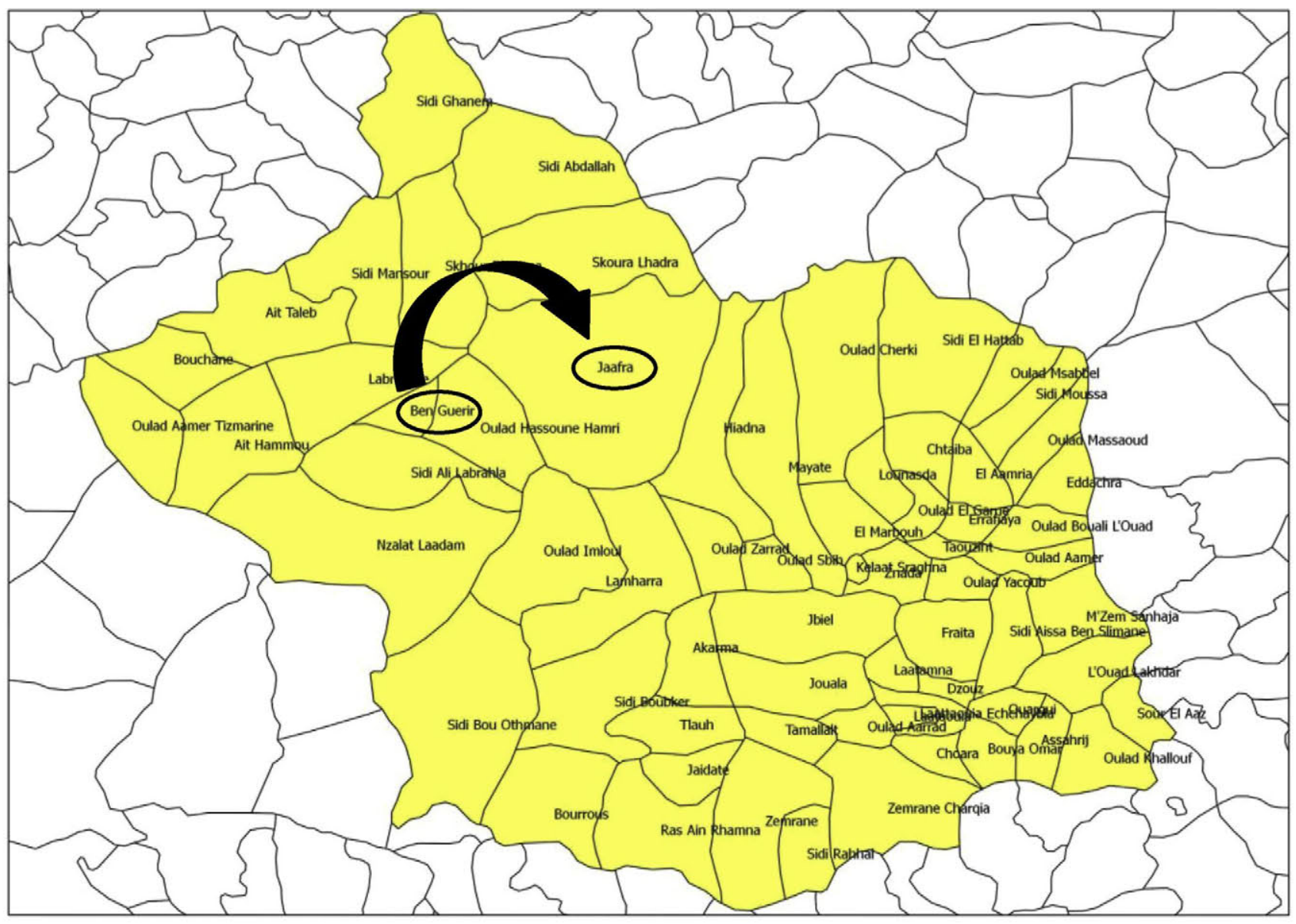

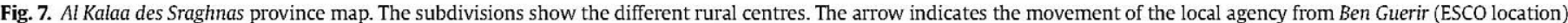
to Jaafra (model location). 
Table 11

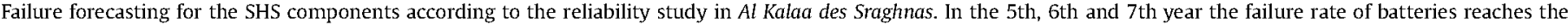
maximum. Batteries and charge controllers are replaced in the user dwelling. Lamps are replaced in the souk.

\begin{tabular}{|c|c|c|c|c|c|c|c|c|c|c|}
\hline Year & 1 & 2 & 3 & 4 & 5 & 6 & 7 & 8 & 9 & 10 \\
\hline Batteries & 31 & 158 & 507 & 777 & 1,002 & 1,076 & 985 & 836 & 745 & 755 \\
\hline Charge controllers & 43 & 98 & 167 & 167 & 167 & 167 & 167 & 167 & 125 & 70 \\
\hline Total & 74 & 256 & 674 & 944 & 1,169 & 1,243 & 1,152 & 1,003 & 870 & 825 \\
\hline
\end{tabular}

Table 12

Optimisation model results compared to the actual data for Al Kalaa des Sraghmas.

\begin{tabular}{lll}
\hline Output parameters & Model results & ESCO real data \\
\hline Local Agency location $\left(B L_{r}\right)$ & $\mathrm{R}=\mathbf{1}(\mathbf{1}$ local agency located in AHLAF) & 1 local agency located in BEN SLMANE \\
Vehicles $\left(N C R_{r}\right)$ & 1 vehicle & 1 vehicle \\
O\&M technicians & 2 technicians & 2 technicians \\
Local structure costs (€/year) & 29,012 & 29,012 \\
Travel costs (fuel) (€/year) & 1165 & 977 \\
O\&M annual cost $(€)$ & 30,177 & 29,989 \\
\hline
\end{tabular}

As regards the $\mathrm{CM}$, there will be around $346 \mathrm{~h}$ per year available for corrective maintenance services. The highest number of corrective maintenance services will also take place during the sixth year (see Table 11). The number of corrective maintenance visits during the sixth year corresponds to 1076 batteries +167 charge controllers $=1243 \mathrm{CM}$ services. around $414 \mathrm{~h}$ will be necessary, more than the time available, according to the model (346 h are enough to carry out $1040 \mathrm{CM}$ services). As shown in Table 12 , only the 5 th, 6 th and 7 th years have more than $1040 \mathrm{CM}$ services to be carried out, thus the maintenance structure calculated by the model will be suitable for the remaining maintenance period. Just during these 3 critical years, it will be necessary to extend the number of maintenance teams from 3 to 4 . This means that during these 3 years the costs of two technicians and 1 vehicle must be added to the cost structure, which has been considered in the resulting costs shown in Table 10 .

\subsection{Example 3: Ben Slimane}

This province is made up of 8 rural communities and has 857 SHSs, the results of the model optimisation are shown in Table 12 , taking into account the same time parameters as defined in Table 6:

The results show that both the model solution and ESCO real data are very similar. Note that the model has moved the local agency.

As regards the $C M$, there will be around $195 \mathrm{~h}$ per year available for corrective maintenance services. The highest number of corrective maintenance services in this province will also take place during the sixth year. The number of corrective maintenance services during the sixth year corresponds to 212 batteries +34 charge controllers $=246 \mathrm{CM}$ services. Around $82 \mathrm{~h}$ will be necessary, less than the $195 \mathrm{~h}$ available, according to the model results.

\section{Conclusions}

A special case study based on the Moroccan Photovoltaic Rural Electrification Program has been developed to illustrate the performance of an optimisation tool, based on a mixed integer linear optimisation model, intended to design maintenance structures in decentralised PVREs. The model has been formulated in accordance with the technical and O\&M specifications of the Moroccan program, imposed by the local utility. These rules have determined some of the constraints included in the optimisation model to ensure the operability and quality of maintenance service.

The purpose of the tool is to obtain an optimised maintenance structure in terms of number of technicians and vehicles and the best location for the local agencies, able to satisfy all the constraints defined, to guarantee the SHSs' maintenance service and the fee collection carried out in the local markets (souks).

The defined objective function must minimise the associated costs of:

- Location of local agencies

- Vehicles and technicians

- Maintenance and fee collection journeys

The usefulness of the tool has been illustrated using three of the provinces belonging to the PERG program.

The results of the application show that, in two cases, the model solution matches the real ESCO data in these provinces, which suggests that the ESCO optimised the maintenance structure and costs in these cases. In the other province, the model has optimised the maintenance structure by reducing the number of maintenance teams by 1 ( 2 technicians and 1 vehicle) during 7 of the 10 years of the maintenance period; it has relocated the local agency to a better location and it has optimised the maintenance journeys. Thus, the cost of the O\&M in this province has been reduced by $19.5 \%$. This optimisation can be explained as this province has a high number of SHSs (4396 SHSs, one third of the total amount) it is intuitive to think that the organization of maintenance in this province was harder than in other provinces with far fewer SHSs (Ben Slimane had 857 and Azilal 1809). Therefore, it was expected that if the tool could provide a reduction in cost and structure, it would happen in this province.

Through these results, the potential usefulness of this tool to help ESCOs in the design of the maintenance structures in PVRE programs based on the knowledge of the reliability parameters of the SHSs and the operating costs has been shown.

The application of the tool to this case study has been useful in identifying some improvements, such as the convenience of considering some input data in a range and tolerance, instead of average data, in order to make the results more realistic. In future research it is also intended to give more generality to the tool in such a way it can be adapted and applied to other PVRE programs 
with different kinds of technical features and management requirements.

\section{Acknowledgements}

The first author would like to thank Isofoton Maroc s.a.r.l., of which I was part of the management team during the first five years of development of the PERG program in Morocco, which have given me the opportunity to compile all the data and expertise necessary to carry out this work.

The authors would like to thank Marta Artalejo Álvarez, MSc, for her valuable collaboration.

This work has been partially supported by the Government of Spain, TIN2012-32482, and by the local Government of Madrid, grant S2013/ICE-2845 (CASI-CAM).

\section{References}

[1] Ouedraogo NS. Energy consumption and human development: evidence from a panel cointegration and error correction model. Energy 2013;63:28-41.

[2] Aklin M, Bayer P, Harish SP, Urpelainen J. Quantifying slum electrification in India and explaining local variation. Energy 2015;80:203-12.

[3] Balachandra P. Dynamics of rural energy access in India: an assessment. Energy September 2011;36(9):5556-67.

[4] Levin T, Thomas VM. Utility-maximizing financial contracts for distributed rural electrification. Energy 2014;69:613-21.

[5] Nerini FF, Broad O, Mentis D, Welsch M, Bazilian M, Howells M. A cost comparison of technology approaches for improving access to electricity services. Energy January 2016;95(15):255-65.

[6] Johnson NG, Bryden KM. Energy supply and use in a rural West African village. Energy July 2012;43(1):283-92.

[7] IDCOL, [http://www.idcol.org/old/bd-map/bangladesh map/], access in September 2016

[8] Cabraal A. Experiences and lessons from 15 years of World Bank support for photovoltaics for off-grid electrification. In: 2nd international conference on the developments in renewable energy technology (ICDRET); January 2012. p. 1-4. Dakha (Bangladesh).

[9] Lemaire X. Off-grid electrification with solar home systems: the experience of a fee-for-service concession in South Africa. Energy Sustain Dev 2011;15(3): 277-83.

[10] Lemaire X. Fee-for-service companies for rural electrification with photovol taic systems: the case of Zambia. Energy Sustain Dev 2009;13(1):18-23.
[11] Tsikalakis A, Tomtsi T, Hatziargyriou ND, Poullikkas A, Malamatenios Ch, Giakoumelos $\mathrm{E}$, et al. Review of best practices of solar electricity resources applications in selected Middle East and North Africa (MENA) countries. Renew Sustain Energy Rev 2011;15(6):2838-49.

[12] Notton G, Muselli M, Poggi P. Costing of a stand-alone photovoltaic system. Energy 1998;23(4):289-308.

[13] Qoaider L, Steinbrecht D. Photovoltaic systems: a cost competitive option to supply energy to off-grid agricultural communities in arid regions. Appl Energy 2010:87(2):427-35.

[14] Azimoh CL, Klintenberg P, Wallin F, Karlsson B. Illuminated but not electrified: an assessment of the impact of Solar Home System on rural households in South Africa. Appl Energy October 2015;155:354-64.

[15] Nieuwenhout FDJ, van Dijk A, Lasschuit PE, van Roekel G, van Dijk VAP, Hirsch D, et al. Experience with solar home systems in developing countries: a review. Prog. Photovolt. Res Appl 2001;9:455-74.

[16] Linguet L, Hidair l. A detailed analysis of the productivity of solar home system in an Amazonian environment. Renew Sustain Energy Rev February 2010;14(2):745-53.

[17] Lu M. AD HOC regionalism in rural development. Geogr Rev July 2011;101(Issue 3):334-52.

[18] Brocco A. Ad-hoc self-organized microgrid for rural electrification and postdisaster response. In: 2013 IEEE green technologies conference (GreenTech); April 2013. p. 315-21. Denver, CO (USA).

[19] Beasley JE. Advances in linear and integer programming. Oxford University Press; 1996.

[20] Jamrani A. The Moroccan general rural electrification programme (PERG). In: Proceedings of the ISES 2000 utility initiative for Africa seminar: rural electrification in Africa, Midrand (South Africa); April 2000. p. 17-8.

[21] Carrasco LM, Navarte I, Peral A, Vázquez M. Reliability of a 13,000-SHS photovoltaic rural electrification program. Prog Photovolt. Res Appl 2013;21: $1136-45$.

[22] Carrasco LM, Narvarte L, Martínez-Moreno F, Moretón R. In-field assessment of batteries and PV modules in a large photovoltaic rural electrification program. Energy 2014;75:281-8.

[23] Carrasco LM, Navarte L, Lorenzo E. Operational costs of A 13.000 solar home systems rural electrification program. Renew Sustain Energy Rev 2013;20: $1-7$.

[24] Rosenthal RE. Gams A User's Guide. Washington. DC. USA. Gams Development Corporation; 2014

[25] User's manual for Cplex. IBM ILOG; 2014

[26] Mitchell JE. Branch-and-cut algorithms for combinatorial optimization problems, handbook of applied operations research. Oxford University Press; 2002. p. $65-77$.

[27] Kousksou T, Allouhi A, Belattar M, Jamil A, El Rhafiki T, Zeraouli Y. Morocco's strategy for energy security and low-carbon growth. Energy 2015;84:98-105. 